\title{
Molecular Redox: Revisiting the Electronic Structures of the Group 9 Metallocorroles
}

\author{
Joshua H. Palmer*, ${ }^{* \dagger}$ and Kyle M. Lancaster*, \\ ${ }^{\perp}$ Beckman Institute, California Institute of Technology, Pasadena, California 91125, United States \\ ${ }^{\ddagger}$ Department of Chemistry and Chemical Biology, Cornell University, Baker Laboratory, Ithaca, New York 14853, United States
}

\section{Supporting Information}

ABSTRACT: The electronic structures of monocationic tris $[(5,10,15$-pentafluorophenyl)-corrolato $]$ iridium compounds, $\left[\operatorname{Ir}(\mathrm{tpfc}) \mathrm{L}_{2}\right]^{+}$, where $\mathrm{L}=4$-cyanopyridine $[1]^{+}$, pyridine $[2]^{+}$, 4-methoxypyridine $[3]^{+}$, or $4-\left(N, N^{\prime}-\right.$ dimethylamino)pyridine $[4]^{+}$, have been probed by electron paramagnetic resonance (EPR) spectroscopy, Ir $\mathrm{L}_{3,2}$-edge $\mathrm{X}$ ray absorption spectroscopy (XAS), UV/visible (UV-vis) spectroelectrochemistry, and density functional theoretical

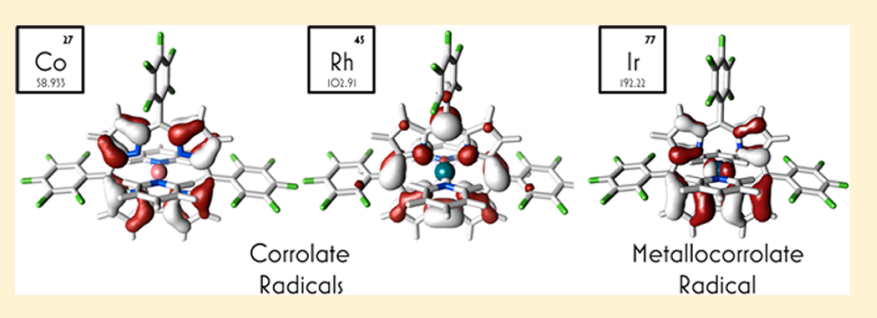
(DFT) calculations. The data demonstrate that these complexes, which have been previously formulated as either of the limiting cases $\left[\mathrm{Ir}^{\mathrm{III}}\left(\mathrm{tpfc}^{\bullet}\right) \mathrm{L}_{2}\right]^{+}$or $\left[\mathrm{Ir}^{\mathrm{IV}}(\mathrm{tpfc}) \mathrm{L}_{2}\right]^{+}$, are best described as possessing a singly occupied molecular orbital (SOMO) dominated by tpfc with small but significant Ir admixture. EPR $g$-values and electronic absorption spectra are reproduced well using a simple DFT approach. These quantities depend profoundly upon Ir orbital contribution to the SOMO. To wit, the calculated Ir spin population ranges from $10.6 \%$ for $[1]^{+}$to $16.3 \%$ for $[4]^{+}$, reflecting increased Ir d mixing into the SOMO with increasingly electron-rich axial ligation. This gives rise to experimentally measured $g_{z}$ values ranging from 2.335 to 2.533 , metalto-ligand charge transfer (MLCT) bands ranging from 14730 and $14330 \mathrm{~cm}^{-1}$, and $\left[\operatorname{Ir}(\mathrm{tpfc}) \mathrm{L}_{2}\right]^{+/ 0}$ reduction potentials ranging

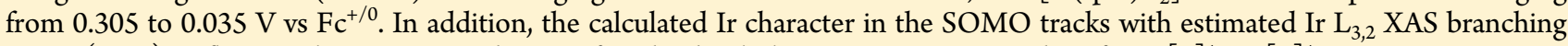
ratios (EBR), reflecting the increasing degree of $\operatorname{Ir} d$ orbital character upon proceeding from $[\mathbf{1}]^{+}$to $[4]^{+}$.

\section{INTRODUCTION}

The location of unpaired electron density in open-shell transition metal coordination complexes profoundly influences their reactivity. ${ }^{1}$ Thorough evaluation of the electronic structures of a large assortment of such compounds reveals that ligands often behave in "non-innocent" fashion; that is to say, the locus of redox activity (and thus the d electron count on the metal) is ambiguous. ${ }^{2}$ Cases contrasting ligand- versus metal-centered redox have included, among others, studies of complexes with dithiolene, ${ }^{3}$ polypyridyl, ${ }^{4}$ bis-iminopyridine, ${ }^{5}$ and aza-allyl ligands. ${ }^{6}$ However, appreciable metal-ligand admixture in redox-active MOs can confound the distinction between metal- and ligand-centered redox behavior. Transition metal complexes with such frontier orbitals pervade chemistry and biology. For example, substantial ${ }^{35 / 37} \mathrm{Cl}$ superhyperfine coupling (SHFC) in the electron paramagnetic resonance (EPR) spectrum of $\left[\mathrm{IrCl}_{6}\right]^{2-}$ indicates $\sim 30 \% \mathrm{Cl} 3 \mathrm{p}$ character in the singly occupied $\mathrm{MO}$ (SOMO) of this classical coordination complex. ${ }^{7}$ In biology, the "blue copper" centers feature $\mathrm{Cu}-\mathrm{S}$ bonds in which $\sim 40 \%$ of the unpaired electron density is localized over the thiolate, suggesting that their redox cycles may be more appropriately described as $\{\mathrm{Cu}-\mathrm{S}\}^{+/ 0}$ than as $\mathrm{Cu}^{\mathrm{II} / \mathrm{I}} 8$

The deprotonated corrole macrocycle, or corrolate, has been extensively discussed within the context of redox noninnocence. ${ }^{9}$ Originally touted as electron-rich platforms for the stabilization of transition metals in high oxidation states, corrolates have often been found to exhibit a high degree of non-innocence, that is, orbitals with significant ligand character are redox-active. ${ }^{10}$ Cases of particular interest include the copper corrolates, which have been described as either $\mathrm{Cu}^{\mathrm{II}}\left(\operatorname{cor}^{\bullet+}\right)^{11}$ or $\mathrm{Cu}^{\mathrm{III}}(\mathrm{cor}),{ }^{12}$ and the chloroiron corrolates. These latter componds were the subject of a great deal of discussion during the first decade of this century, with Gross and co-workers arguing for an $\mathrm{Fe}^{\mathrm{IV}}$ (cor) $\mathrm{Cl}$ description ${ }^{13}$ while Walker and colleagues advanced a $\mathrm{Fe}^{\mathrm{III}}\left(\mathrm{cor}^{\bullet+}\right) \mathrm{Cl}$ formalism ${ }^{14}$ The general consensus at this point is that these complexes are better described as $\mathrm{Fe}^{\mathrm{III}}\left(\right.$ cor $\left.^{\bullet+}\right) \mathrm{Cl}$ than as $\mathrm{Fe}^{\mathrm{IV}}$ (cor) $\mathrm{Cl}^{15}$ Metal corrolates have also been the focus of intense research in recent years because of their possible applications ${ }^{16}$ in catalysis, ${ }^{17}$ medicine, ${ }^{18}$ and optics. ${ }^{19}$

We have reported and fully characterized neutral corrolato complexes of iridium, ${ }^{20}$ which exhibit near-IR phosphorescence $^{21}$ and unique ring-opening reactivity, ${ }^{22}$ but we have not provided a consensus description of the electronic structures of their monocations. Preliminary EPR data indicated substantial $g$-anisotropy suggestive of $\operatorname{Ir}^{\mathrm{IV}}$ centers in $\left[\operatorname{Ir}(\mathrm{tpfc})(\mathrm{tma})_{2}\right]^{+}$and $\left[\operatorname{Ir}(\mathrm{tpfc})(\mathrm{py})_{2}\right]^{+}\left[(\mathrm{tpfc})^{3-}=\right.$ tris(pentafluorophenylcorrolato $)$, tma $=$ trimethylamine, py $=$ pyridine $].{ }^{23}$ However, a density functional theoretical (DFT) study of $\left[\operatorname{Ir}(\mathrm{tpfc})\left(\mathrm{NH}_{3}\right)_{2}\right]$ and its $\mathrm{Co}$ and $\mathrm{Rh}$ congeners revealed a consistently corrole-

Received: August 28, 2012

Published: November 1, 2012 
dominated highest occupied molecular orbital (HOMO) for these neutral, closed-shell molecules. ${ }^{24}$ The anisotropic EPR spectra of the monocations were postulated to arise from spinorbit coupling (SOC) of the corrolato $\pi$-radical cation to the Ir $^{\mathrm{III}}$ center.

Here we present a combined spectroscopic and theoretical study of a series of monocationic Ir corrolato complexes bearing substituted pyridine ligands (Chart 1). Our data

\section{Chart 1. Compounds under Study ${ }^{a}$}

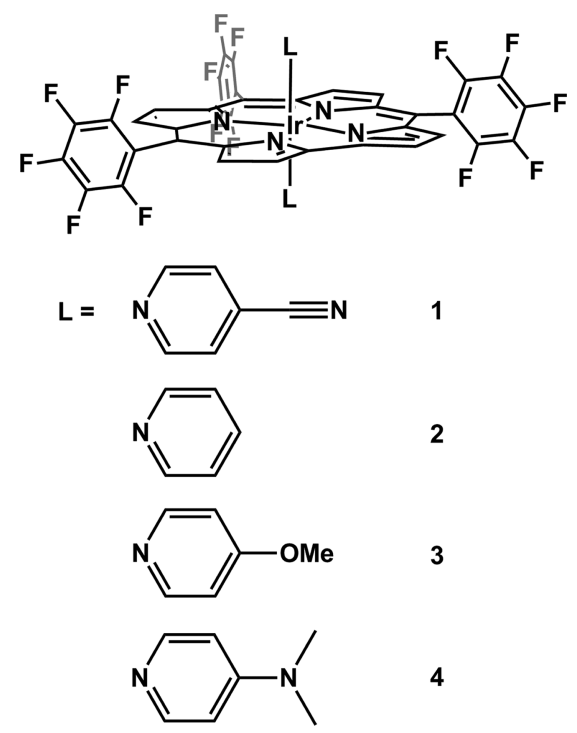

${ }^{a} \mathrm{~L}$ is bound by the heterocyclic nitrogen atom.

indicate that these complexes are best considered corrole radicals with small but significant Ir character mixed into their SOMOs. This mixing affords sufficient orbital angular momentum to give rise to highly anisotropic EPR spectra; our calculations reproduce trends in EPR, UV-vis, and X-ray absorption spectroscopic behavior without requiring a theoretical framework that accounts for ground-state SOC of the corrolato radical to Ir. These data invite caution against assignment of highly anisotropic EPR spectra alone as fingerprints of metal-based SOMOs. They also indicate that, for many systems, the "metal-centered" versus "ligandcentered" redox paradigm is likely inadequate; rather, the redox of the system must be described from a delocalized, molecular perspective.

\section{EXPERIMENTAL SECTION}

General Considerations. Solvents were purchased from EMD Chemicals, J.T. Baker, and VWR, and were used without further purification. Solvents used for air- and moisture-sensitive reactions were degassed with argon and dried on columns of activated alumina. Deuterated NMR solvents were purchased from Cambridge Isotope Laboratories or Sigma-Aldrich and were used as received. $\mathrm{H}_{3}$ tpfc was obtained via a literature method, ${ }^{25}$ as was Compound $2 .{ }^{23}$ All other reagents were purchased from Sigma-Aldrich and used as received. ${ }^{1} \mathrm{H}$ NMR experiments were performed on two different Varian Mercury $300 \mathrm{MHz}$ NMR spectrometers and one Varian Mercury $600 \mathrm{MHz}$ NMR spectrometer. All ${ }^{19} \mathrm{~F}$ NMR experiments were performed on one of the $300 \mathrm{MHz}$ spectrometers. ${ }^{1} \mathrm{H}$ NMR spectra are reported in ppm relative to $\mathrm{SiMe}_{4}(\delta=0)$ and were referenced internally with respect to the protio solvent impurity $\left(\delta=7.26\right.$ for $\left.\mathrm{CHCl}_{3}\right) .{ }^{19} \mathrm{~F}$ NMR spectra are reported in ppm relative to $\mathrm{CFCl}_{3}(\delta=0)$ and were referenced using an external standard. NMR coupling constants are given in hertz. Mass spectrometry was performed by electrospray ionization into an Agilent G1956B LC-MS. Solutions of $1-10 \mu \mathrm{M}$ analyte concentration were prepared in $\mathrm{CH}_{3} \mathrm{OH}$ for injection when possible; in the case of material less soluble in methanol, a mix of $7: 3 \mathrm{CH}_{3} \mathrm{OH} / \mathrm{CHCl}_{3}$ was employed instead. Ions were probed primarily in positive mode. Electronic spectra were obtained on a Varian Cary 60 Scanning Spectrophotometer. The error in reported wavelength values is at most $\pm 0.5 \mathrm{~nm}$.

Sample Preparation. All neutral complexes were synthesized via the following procedure, modified from the literature: ${ }^{23} \mathrm{H}_{3} \mathrm{tpfc}^{25}$ (40 $\mathrm{mg} ; 0.05 \mathrm{mmol}),\left[\mathrm{Ir}^{\mathrm{I}}(\mathrm{cod}) \mathrm{Cl}\right]_{2}(170 \mathrm{mg} ; 0.25 \mathrm{mmol})$, and $\mathrm{K}_{2} \mathrm{CO}_{3}(70$ $\mathrm{mg}$; $0.50 \mathrm{mmol}$ ) were dissolved/suspended in $75 \mathrm{~mL}$ of degassed tetrahydrofuran (THF), and the mixture was heated at reflux under argon for $90 \mathrm{~min}$. Excess metal was employed to ensure maximum conversion, as smaller quantities resulted in lower yields. To this solution was added $0.50 \mathrm{mmol}$ of the appropriate pyridine: 4cyanopyridine (105 mg; 1); 4-methoxypyridine (110 mg; 3); 4-(N,N'dimethylamino)pyridine $(220 \mathrm{mg} ; 4)$. The solution was allowed to slowly cool to room temperature while exposed to atmosphere. Column chromatography of the green reaction mixture (silica, 4:1 hexanes $/ \mathrm{CH}_{2} \mathrm{Cl}_{2}$ followed by 2:3 hexanes $/ \mathrm{CH}_{2} \mathrm{Cl}_{2}$ ) afforded a bright red solution, which upon evaporation yielded microcrystalline solids 1 (36 mg; 66\%), 3 (28 mg; 50\%), or 4 (30 mg, 49\%).

1: ${ }^{1} \mathrm{H}$ NMR $\left(\mathrm{CDCl}_{3}\right): \delta 8.91(\mathrm{~d}, 2 \mathrm{H}, J=4), 8.60(\mathrm{~d}, 2 \mathrm{H}, J=5)$, $8.39(\mathrm{~d}, 2 \mathrm{H}, J=5), 8.26(\mathrm{~d}, 2 \mathrm{H}, J=4), 5.43\left(\mathrm{~d} / \mathrm{d}, 4 \mathrm{H},{ }^{3} J=7,{ }^{4} J=4\right)$, $1.75\left(\mathrm{~d} / \mathrm{d}, 4 \mathrm{H},{ }^{3} J=7,{ }^{4} J=4\right) .{ }^{19} \mathrm{~F}$ NMR $\left(\mathrm{CDCl}_{3}\right): \delta-138.4(\mathrm{~d} / \mathrm{d}, 2 \mathrm{~F}$, $\left.{ }^{3} J=35,{ }^{4} J=17\right),-139.0\left(\mathrm{~d} / \mathrm{d}, 4 \mathrm{~F},{ }^{3} J=35,{ }^{4} J=17\right),-153.8(\mathrm{t}, 2 \mathrm{~F}, J=$ 22), $-154.1(\mathrm{t}, 1 \mathrm{~F}, J=22),-162.5(\mathrm{~m}, 4 \mathrm{~F}) .-162.8(\mathrm{~m}, 2 \mathrm{~F})$. MS

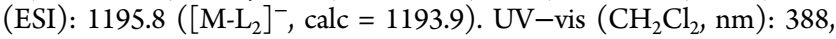
406, 580, 608.

3: ${ }^{1} \mathrm{H}$ NMR $\left(\mathrm{CDCl}_{3}\right): \delta 8.81(\mathrm{~d}, 2 \mathrm{H}, J=4), 8.49(\mathrm{~d}, 2 \mathrm{H}, J=4)$, 8.31 (d, 2H, $J=4), 8.12$ (d, $2 \mathrm{H}, J=4), 4.69$ (d/d, $\left.4 \mathrm{H},{ }^{3} J=7,{ }^{4} J=5\right)$, $2.93(\mathrm{~s}, 6 \mathrm{H}), 1.56(\mathrm{~m}, 4 \mathrm{H}) \cdot{ }^{19} \mathrm{~F} \mathrm{NMR}\left(\mathrm{CDCl}_{3}\right): \delta-138.4\left(\mathrm{~d} / \mathrm{d}, 2 \mathrm{~F},{ }^{3} \mathrm{~J}\right.$ $\left.=36,{ }^{4} J=17\right),-138.6\left(\mathrm{~d} / \mathrm{d}, 4 \mathrm{~F},{ }^{3} J=36,{ }^{4} J=17\right),-155.0(\mathrm{t}, 2 \mathrm{~F}, J=$ $22),-155.4(\mathrm{t}, 1 \mathrm{~F}, J=22),-163.3(\mathrm{~m}, 4 \mathrm{~F}) .-163.7(\mathrm{~m}, 2 \mathrm{~F})$. MS

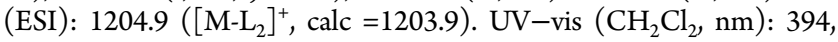
412, 584, 624.

4: ${ }^{1} \mathrm{H}$ NMR $\left(\mathrm{CDCl}_{3}\right): \delta 8.76(\mathrm{~d}, 2 \mathrm{H}, J=4), 8.44(\mathrm{~d}, 2 \mathrm{H}, J=4)$, $8.27(\mathrm{~d}, 2 \mathrm{H}, J=4), 8.05$ (d, $2 \mathrm{H}, J=4), 4.25(\mathrm{~d}, 4 \mathrm{H}, J=8), 2.09(\mathrm{~s}$, $12 \mathrm{H}), 1.41(\mathrm{~d}, 4 \mathrm{H}, J=8) .{ }^{19} \mathrm{~F} \mathrm{NMR}\left(\mathrm{CDCl}_{3}\right): \delta-137.8\left(\mathrm{~d} / \mathrm{d}, 2 \mathrm{~F},{ }^{3} J=\right.$ $\left.34,{ }^{4} J=17\right),-138.1\left(\mathrm{~d} / \mathrm{d}, 4 \mathrm{~F},{ }^{3} J=34,{ }^{4} J=17\right),-151.2(\mathrm{t}, 2 \mathrm{~F}, J=21)$, $-155.6(\mathrm{t}, 1 \mathrm{~F}, J=21),-163.4(\mathrm{~m}, 4 \mathrm{~F}) .-163.7(\mathrm{~m}, 2 \mathrm{~F})$. MS (ESI): $1230.9\left([\mathrm{M}]^{+}\right.$, calc $\left.=1230.0\right)$. UV-vis $\left(\mathrm{CH}_{2} \mathrm{Cl}_{2}, \mathrm{~nm}\right): 393,417,585$, 642.

EPR Spectroscopy. Solutions for EPR were prepared by adding 50

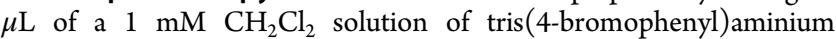
hexachloroantimonate to $50 \mu \mathrm{L}$ of a $1 \mathrm{mM} \mathrm{CH}_{2} \mathrm{Cl}_{2}$ solution of complex. Spectra were recorded using Bruker EMX Biospin instrument equipped with a Gunn diode source delivering X-band (9.5 $\mathrm{GHz}$ ) microwave radiation. Solutions were frozen by rapid immersion in liquid nitrogen; spectra were recorded at $20 \mathrm{~K}$ using an Oxford liquid $\mathrm{He}$ flow cryostat. The SPINCOUNT package was used to simulate EPR spectra. ${ }^{26}$

X-ray Absorption Spectroscopy. Iridium $\mathrm{L}_{3,2}$-edge XAS were collected at the Stanford Synchrotron Radiation Lightsource (SSRL) beamlines 9-3 and 7-3 under ring conditions of $3 \mathrm{GeV}$ and $200 \mathrm{~mA}$. A $\mathrm{Si}(220)$ double-crystal monochromator was used for energy selection, and a Rh-coated mirror (set to an energy cutoff of $13 \mathrm{keV}$ ) was used for harmonic rejection. Internal energy calibration was performed by assigning the first inflection point of a spectrum of finely dispersed $\mathrm{K}_{2}\left[\mathrm{IrCl}_{6}\right]$ on Kapton to $11215 \mathrm{eV}\left(\mathrm{L}_{3}\right)$ or $12824 \mathrm{eV}\left(\mathrm{L}_{2}\right)$. Following the same procedure used for preparing EPR samples, solutions were loaded into $2 \mathrm{~mm}$ Delrin XAS cells with $38 \mu \mathrm{m}$ Kapton windows and glassed by rapid immersion in liquid nitrogen. Data were collected in fluorescence mode (using a Canberra Ge 30-element array detector) with the sample temperature maintained at $10 \mathrm{~K}$ in an Oxford liquid He flow cryostat. 3-5 scans were averaged and processed using the MAVE and PROCESS modules of the EXAFSPAK software package. ${ }^{27}$ Background subtraction was achieved by fitting a polynomial to the pre-edge region and subtracting this polynomial 
from the entire spectrum. Spectra were normalized by fitting a flattened polynomial to the postedge and normalizing the edge jump to 1.0. EXAFS were fit using the OPT module of EXAFSPAK from scattering paths calculated with FEFF7 from optimized geometries. ${ }^{28}$

Electrochemistry and UV-vis Spectroelectrochemistry. All voltammetric measurements were performed using a Pine WaveNow USB Potentiostat/Galvanostat. All electrodes were purchased from Pine as well. Compounds were dissolved at approximately $1 \mathrm{mM}$ concentration in $\mathrm{CH}_{2} \mathrm{Cl}_{2}$ containing $0.1 \mathrm{M}\left[\mathrm{NEt}_{4}\right] \mathrm{PF}_{6}$ as supporting electrolyte. For cyclic voltammetry, a $3 \mathrm{~mm}$ Pt disk working electrode, a coiled Pt wire counter electrode, and a single-junction $\mathrm{Ag} / \mathrm{AgCl}$ reference electrode were employed. Redox potentials are reported relative to the ferrocenium/ferrocene couple. For UV-vis spectroelectrochemical measurements, a gold "honeycomb" spectroelectrochemical card, which contains a transparent Au working electrode mesh and two $\mathrm{Au}$ counter electrode areas, was employed; a separate singlejunction $\mathrm{Ag} / \mathrm{AgCl}$ reference electrode was employed as well. To take each measurement, a given potential was applied to the solution until equilibrium was reached. Then, a UV-vis spectral measurement was made using a Varian Cary 60 Scanning Spectrophotometer.

DFT Calculations. Calculations were performed using the ORCA quantum chemistry suite. ${ }^{29}$ Geometries for neutral and monocationic compounds were optimized using the PW9 $1^{30}$ density functional with a segmented all electron relativistically contracted (SARC) def2TZVP(-f) basis set. ${ }^{31}$ Optimizations included the zeroth order relativistic approximation (ZORA) ${ }^{32}$ for relativistic effects, an empirical correction for van der Waals repulsion (DFT-D) ${ }^{33}$ and solvation as modeled by the conductor-like screening model $(\mathrm{COSMO})^{34}$ using a dielectric of $9.08\left(\mathrm{CH}_{2} \mathrm{Cl}_{2}\right)$.

The B3LYP functional, ${ }^{35}$ in conjunction with the ZORA-optimized SARC def2-TZVP(-f) basis set, was used to generate single-point unrestricted Kohn-Sham (UKS) solutions for EPR calculations. The integration accuracy was set to 4 for light atoms and 7 for Ir. EPR properties were predicted using coupled perturbation Kohn-Sham theory for the $g$-matrix, ${ }^{36}$ and the SOC operator was treated by the spin-orbit mean-field approximation. ${ }^{37}$ Ir contributions to the SOMOs were estimated by Löwdin population analysis of quasirestricted orbital transformations of the UKS solutions. ${ }^{38}$ For comparison, calculations were also performed without ZORA using the nonrelativistic def2-TZVP basis set. ${ }^{39}$

\section{RESULTS AND DISCUSSION}

Synthesis. Substituted pyridine (py) ligands afford a convenient means to parametrically interrogate the electronic structures of monocationic iridium corroles. To this end, we have synthesized complexes coordinated by pyridines bearing electron-withdrawing groups (4-cyanopyridine; 1) and electron-donating groups (4-methoxypyridine; 3, 4- $\left(N, N^{\prime}\right.$ dimethylamino)pyridine, 4), as presented in Chart 1. Their syntheses were effected via modifications of the literature synthesis of the bis-pyridine complex, 2 . The neutral complexes were characterized by NMR, MS, and electronic absorption spectroscopy. Chemical oxidation to the monocationic species was achieved by allowing solutions of the neutral complexes to react with one equivalent of tris(4-bromophenyl)ammoniumyl hexachloroantimonate as previously reported. ${ }^{23}$ Solutions of the monocationic corroles were prepared just prior to data collection; attempts to isolate these complexes have thus far met with no success. EXAFS structural analysis (Supporting Information, Figure S3, Table S1) of the monocations confirmed the integrity of the samples. Additionally, the reversible electrochemistry demonstrates that oxidation is not followed by chemical reaction.

EPR Spectroscopy. Frozen solution X-band EPR spectra of compounds $[\mathbf{1}]^{+}-[\mathbf{4}]^{+}$are presented in Figure 1 , and simulation parameters compiled in Table 1 . These spectra are rhombic, with a large degree of $g$ anisotropy, but display no

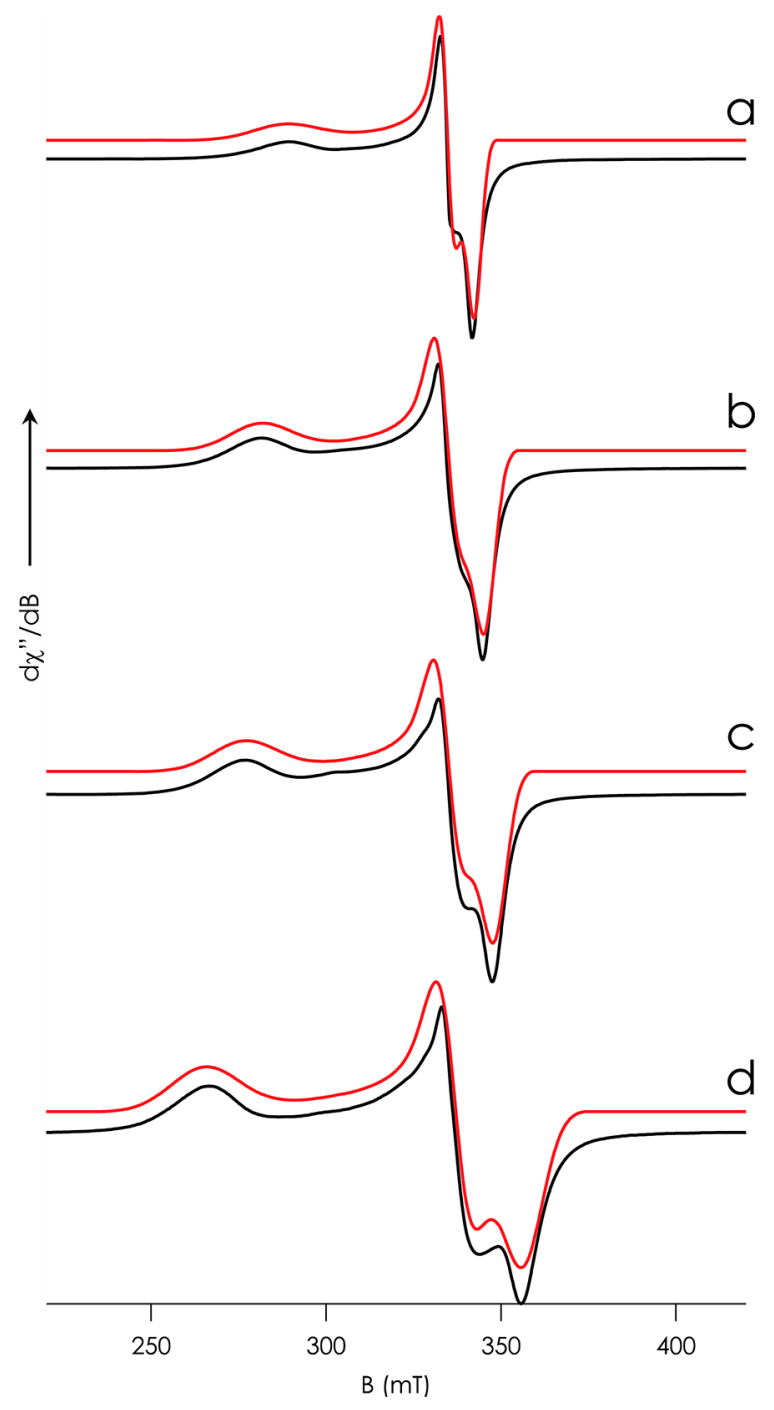

Figure 1. Experimental (black) and simulated (red) X-band EPR spectra of $\left[\operatorname{Ir}(\mathrm{tpfc}) \mathrm{L}_{2}\right]^{+}$complexes recorded in $\mathrm{CH}_{2} \mathrm{Cl}_{2}$ at $20 \mathrm{~K}$ : (a) $[1]^{+}$, (b) $[2]^{+}$, (c) $[3]^{+}$, (d) $[4]^{+}$.

resolvable hyperfine coupling (HFC) assignable to either ${ }^{191 / 193} \mathrm{Ir}$ or ${ }^{14} \mathrm{~N}$. The value of $g_{z}$ increases with the propensity for electron donation by substituents on the pyridine ring, while the value of $g_{x}$ decreases. In short, the spectra become more anisotropic as the pyridine ring becomes more electron rich. This large g-anisotropy prompted the earlier $\operatorname{Ir}^{\mathrm{IV}}$ assignment for the corrolate complexes despite a lack of Ir HFC. ${ }^{23}$ Spectra of recently reported square-planar $\mathrm{Ir}^{\mathrm{II}}$ nitrido complexes also lack ${ }^{191 / 193}$ Ir HFC despite SOMOs bearing substantial ( 50\%) Ir dorbital character. ${ }^{40}$

In the limiting case where the electronic structures of the monocationic complexes under study are considered bona fide $\mathrm{Ir}^{\mathrm{IV}}$ species, we may better understand their EPR spectra using the ligand field (LF) model. We will adopt an approximation that our molecules transform according to the $D_{4 h}$ point group, as if they were symmetrically substituted porphyrins. ${ }^{10 \mathrm{c}}$ The molecular structure of 2 reveals that the pyridine ring bisects the $x$ - and $y$-axes (Figure 2). ${ }^{20}$ The HOMO of py serves as a $\sigma$ donor interacting with $\operatorname{Ir~}_{z}{ }^{2}$. Closely beneath the py HOMO lies a $\pi$-symmetry orbital; donation from this orbital should destabilize $d_{x z}$ and $d_{y z}$ equally. The unpaired electron is then localized in a SOMO that contains an equal admixture of $d_{x z}$ 
Table 1. Experimental $g$-Values for $\left[\operatorname{Ir}(\operatorname{tpfc}) L_{2}\right]^{+}$Complexes Derived from Simulation of Frozen Solution Spectra

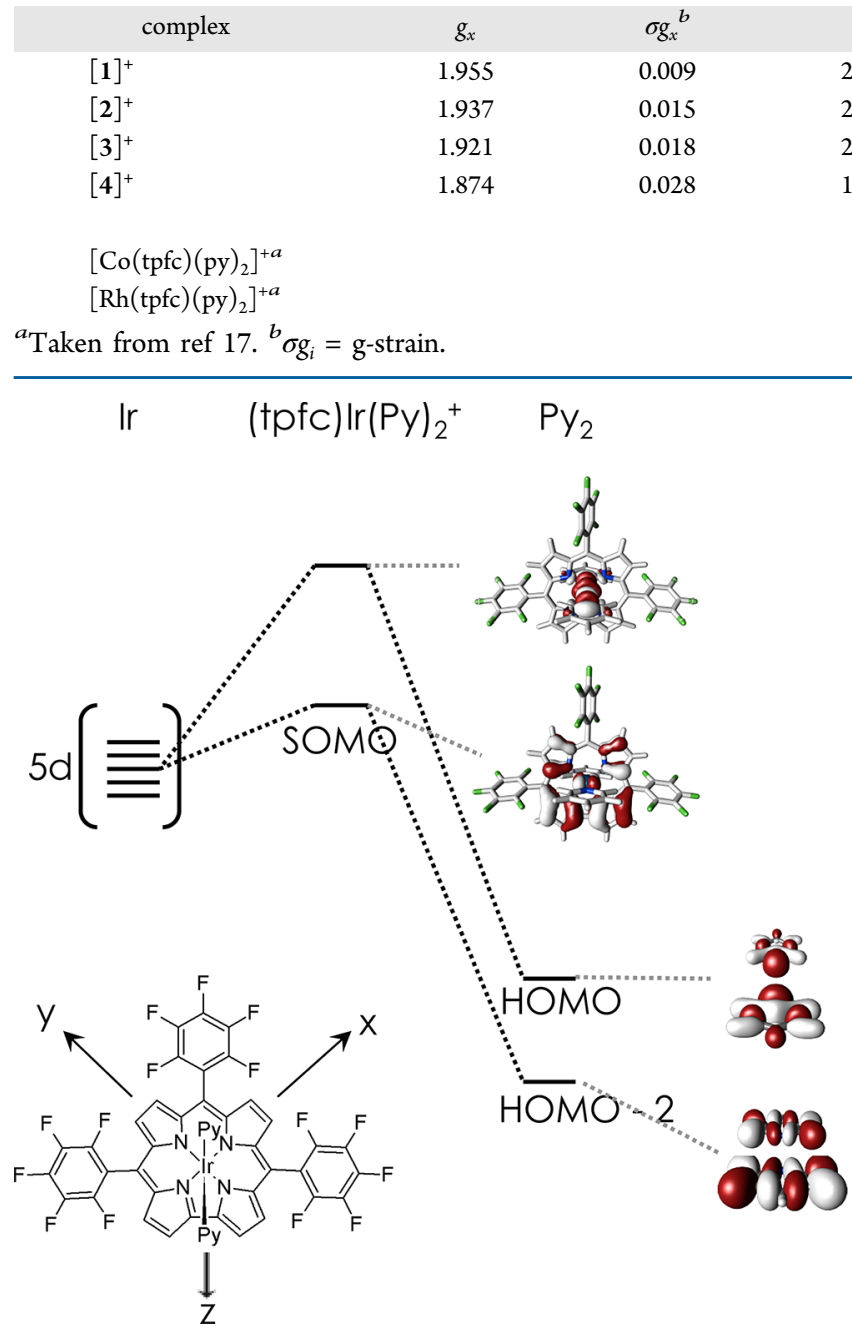

Figure 2. Qualitative, partial $\mathrm{MO}$ diagram of $\left[(\mathrm{tpfc}) \operatorname{Ir}(\mathrm{py})_{2}\right]^{+}$. The py HOMO-2 has $\pi$-symmetry with respect to Ir, although the py-plane bisects the $x$ and $y$ axes defined by Ir-pyrole interactions. As a result, the SOMO features an equal admixture of $\operatorname{Ir} 5 \mathrm{~d}_{x z}$ and $5 \mathrm{~d}_{y z}$. The dominant Ir-Py interaction is via the Py HOMO, which features a lone pair in a lobe possessing $\sigma$-symmetry with respect to Ir. Orbitals are plotted at an isovalue of 0.03 .

and $d_{y z}$. Thus, returning to our limiting case, the SOMO is given by

$$
\psi \simeq\left(\alpha_{y z} \mathrm{~d}_{y z}+\alpha_{x z} \mathrm{~d}_{x z}\right)-\sqrt{\left(1-\alpha_{y z}{ }^{2}+\alpha_{x z}{ }^{2}\right)} \psi_{L}
$$

Here, $\alpha_{\mathrm{d}}$ gives the coefficient of each d orbital in the MO. We have aggregated all ligand contributions (corrole and axial) into a $\psi_{\mathrm{L}}$ orbital that mixes with $\mathrm{d}_{x z, y z}$ to give the SOMO. Perturbation theory then gives the following expression for $g_{z}:^{41}$

$$
g_{z}=2 \lambda\left(\frac{\alpha_{y z}^{2}}{\delta_{x z}}+\frac{\alpha_{x z}^{2}}{\delta_{y z}}\right)+g_{e}
$$

where $\lambda$ is the SOC energy associated with $\operatorname{Ir}, g_{\mathrm{e}}$ is the freeelectron $g$-value, and $\delta_{i}$ indicates the energetic separation between the SOMO and d orbitals. Returning to our original postulate that $\mathrm{d}_{x z}$ and $\mathrm{d}_{y z}$ are destabilized to an equal extent and that the SOMO features equal contributions from these orbitals, we may simplify our expression to

$\begin{array}{ccccc}g_{y} & \sigma g_{y}{ }^{b} & g_{z} & \sigma g_{z}{ }^{b} & \langle g\rangle \\ 2.003 & 0.008 & 2.335 & 0.073 & 2.098 \\ 2.003 & 0.016 & 2.390 & 0.072 & 2.110 \\ 2.002 & 0.019 & 2.431 & 0.079 & 2.118 \\ 1.991 & 0.024 & 2.533 & 0.092 & 2.133 \\ & & & & \\ & & & & 2.008 \\ & & & & \end{array}$

$$
g_{z}=2 \lambda\left(\frac{2 \alpha_{x z / y z}{ }^{2}}{\delta_{x z / y z}}\right)+g_{e}
$$

Approximating that $\lambda$ will vary minimally among the complexes under investigation, we posit that differences among their EPR spectra will principally reflect perturbations to electronic excitations and metal-ligand covalency. The equations describing the positions of the $g_{y}$ and $g_{x}$ components of the $g$-matrix in this system are functions of multiple excitations and feature nonzero off-diagonal terms (see Supporting Information), rendering them less useful for our purposes. Therefore, our analysis focuses on the $g_{z}$ component, which bears a direct correlation with Ir $5 d$ contributions to the SOMO.

Electronic Absorption Spectroscopy. The electronic absorption spectra of the compounds under study are replete with intense charge transfer (CT) bands, precluding direct observation of ligand field excitations (Figure 3). Nevertheless, comparison of the spectral features of the monocationic complexes affords insight into the electronic structural perturbations effected by varying pyridine substituents. Clean conversion of the neutral complexes to their monocations was readily achieved via electrolysis, as evidenced by well-defined isosbestic points in electronic absorption spectra. Midpoint potentials $\left(E_{1 / 2}\right)$ for these conversions were determined by cyclic voltammetry (CV, Table 2, Supporting Information, Figure S13). $E_{1 / 2}$ decreases in the order $1>2>3>4$, indicative of progressively more electron-rich redox centers. Thus, the axial ligands contribute significantly to the electronics of the SOMO, and it is noteworthy that the reduction potential of the complexes can be shifted by $270 \mathrm{mV}$ via simple changes to said ligands. As reported previously, ${ }^{23}$ oxidation of $\{\operatorname{Ir}(\operatorname{tpfc})\}$ complexes results in depletion of Q-band absorption and broadened, attenuated Soret regions. For each complex, a new absorption feature grows in near $14,500 \mathrm{~cm}^{-1}$ that we assign as a predominantly SOMO $\rightarrow$ LUMO excitation (Table 2 ). This assignment is based on time-dependent (TD)-DFT calculations (vide infra), and is supported by the observation that electronic absorption energies track with reduction potentials.

X-ray Absorption Spectroscopy. We have employed Ir $\mathrm{L}_{3,2}$-edge XAS to probe the degree of Ir-centered oxidation. Ir $\mathrm{L}_{3,2}$ edge XAS measures excitations from the Ir $2 \mathrm{p}$ orbital into unoccupied MOs and the continuum. The weaker, higher energy $L_{2}$ excitation produces a final state where SOC between the unpaired $\mathrm{p}$ electron's orbital and spin angular momenta results in a $J$ of $1 / 2$, while the stronger, lower energy $L_{3}$ excitation results in a final state with a $J$ of $3 / 2$. The branching ratio, essentially the intensity ratio of the $\mathrm{L}_{3}$ - and $\mathrm{L}_{2}$-edges, has been used as a metric of metal oxidation state. ${ }^{42}$ Case in point, this estimated branching ratio (EBR) increases linearly as Ir 

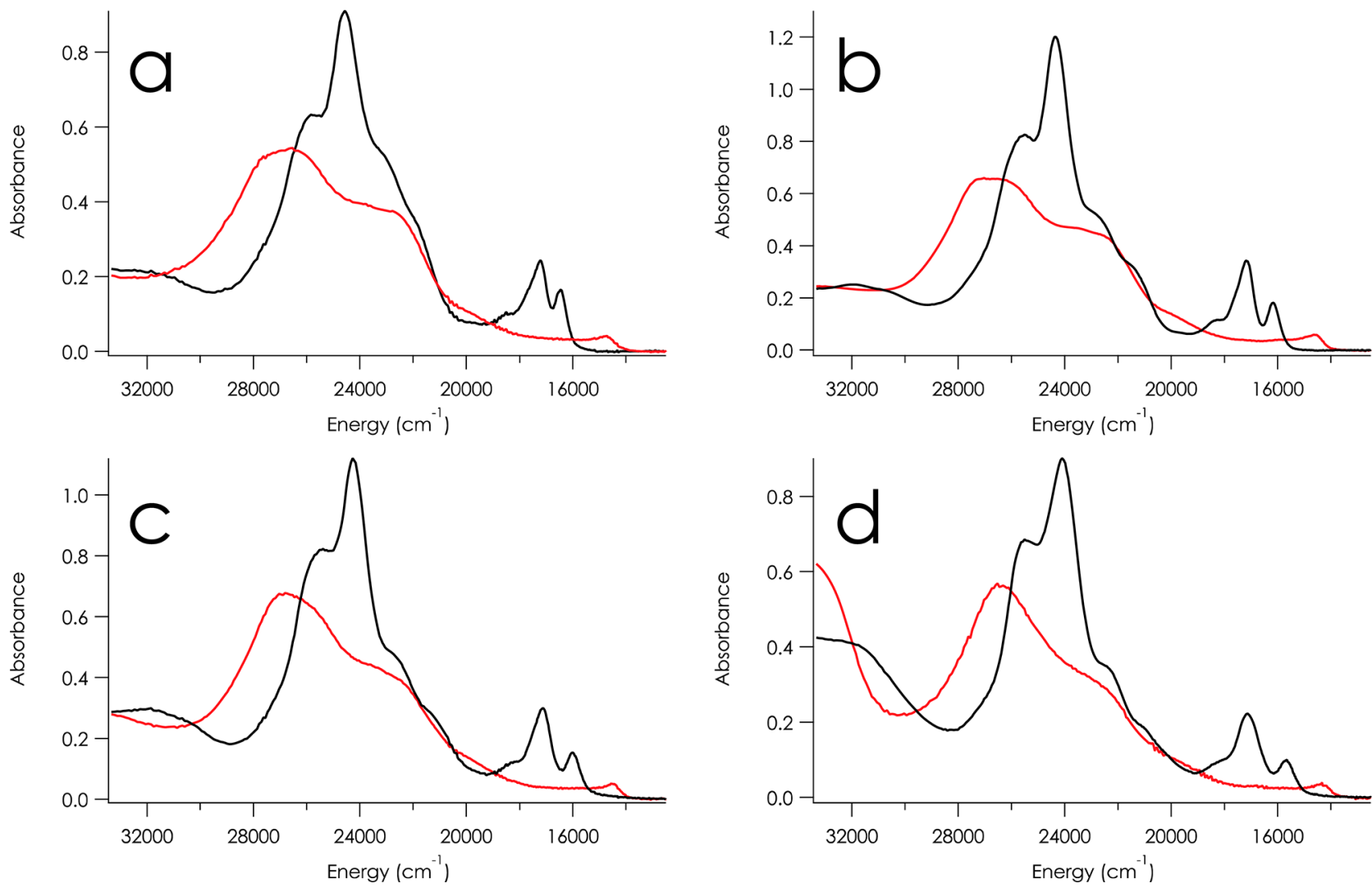

Figure 3. Spectroelectrochemistry of $\left[\operatorname{Ir}(\operatorname{tpfc}) \mathrm{L}_{2}\right]^{+/ 0}$ complexes. Neutral complexes are shown in black and monocations in red; (a) 1, (b) 2, (c) 3, (d) 4 .

Table 2. Spectroelectrochemical Data

$\begin{array}{ccc}\text { complex } & E_{1 / 2}(\mathrm{~V})^{a} & \lambda_{\max }\left(\mathrm{cm}^{-1}\right)^{b} \\ {\left[\mathbf{1}^{+}\right.} & 0.305 & 14730 \\ {[\mathbf{2}]^{+}} & 0.155 & 14560 \\ {[\mathbf{3}]^{+}} & 0.123 & 14470 \\ {[\mathbf{4}]^{+}} & 0.035 & 14330\end{array}$

${ }^{a}$ Versus $\mathrm{Fc}^{+/ 0}$. ${ }^{b} \mathrm{SOMO} \rightarrow$ LUMO transition of monocationic complexes.

oxidation states increase, which can be seen by comparing the spectra of $\left[\mathrm{Ir}^{\mathrm{I}}(\operatorname{cod}) \mathrm{Cl}\right]_{2}, \mathrm{~K}_{3}\left[\mathrm{Ir}^{\mathrm{III}} \mathrm{Cl}_{6}\right]$, and $\mathrm{K}_{2}\left[\mathrm{Ir}^{\mathrm{IV}} \mathrm{Cl}_{6}\right]$ (Supporting Information, Figure S2).

Ir $\mathrm{L}_{3,2}$-edge XAS for the neutral metallocorroles and their corresponding monocations are presented in Figure 4. We note that geometric differences between the neutral and monocationic complexes lead to intensity redistributions from multiplet effects; these prohibit a quantitative assignment of metallocorrole oxidation state using the aforementioned standards. A similar situation has recently been reported for a series of $U$ complexes, although there the discussion centered on $\mathrm{L}_{3}$-edge energies. ${ }^{43}$ Nevertheless, the decreased EBR exhibited by the monocationic species relative to their neutral analogues is consistent with modest Ir-centered oxidation of the complexes. The differences between the neutral and the monocation EBR values trend $[1]^{+}<[2]^{+}<[4]^{+} .^{44}$ Furthermore, these differences in EBR correlate linearly with the value of $g_{z}$ measured for the monocations (Figure 5). These observations support increased Ir contributions to the SOMO as a mechanism for enhanced $g$-anisotropy.
Scalar Relativistic Density Functional Theory. Crystal structures of $\left[(\mathrm{tpfc}) \mathrm{IrL}_{2}\right]^{+}$have thus far proven elusive. As such, calculations of their molecular and electronic structures were performed using geometries optimized at the PW91/def2TZVP(-f)+ZORA level. Oxidation of the neutral iridium corrolates exerts only subtle effects on calculated geometric structures. The major consistent change is a nearly $0.04 \AA$ increase in Ir-L distances. Functional dependence was observed for Ir Löwdin spin populations. Contrary to previous observations in studies of $\mathrm{Fe}$ corroles, ${ }^{14 \mathrm{~b}}$ pure functionals (BP86, PW91, PBE) tended to give solutions with higher metal character than hybrid (B3LYP) and meta-hybrid (TPSSh) functionals. However, trends in spin populations and calculated EPR parameters throughout the series were independent of the functional used. As such, we have restricted our discussion to calculations at the B3LYP/def2-TZVP(-f)+ZORA level.

The SOMOs of all of the monocationic iridium corrolato complexes are predominantly corrole-based (Figure 6). However, maintaining our coordinate system (vide supra), variable amounts of Ir $5 \mathrm{~d}$ character, equally distributed between $\mathrm{d}_{x z}$ and $\mathrm{d}_{y z}$ contribute to these SOMOs (Table 3). The calculated quantity of Ir $5 \mathrm{~d}$ character increases from $10.6 \%$ to $16.3 \%$ in the order $[1]^{+}<[2]^{+}<[3]^{+}<[4]^{+}$. Increased charge donation from more electron-rich axial ligands correlates with an increased percentage of metal character in the SOMO. By contrast, the SOMOs of the Co and Rh congeners completely lack metal $\mathrm{d}$ character.

Computed electronic structure solutions were subsequently used as starting points for $g$-value calculations (Table 3 ). In accord with experiment, ${ }^{23}$ the $g$-values for the analogous Co and $\mathrm{Rh}$ monocations are isotropic and centered near the free- 

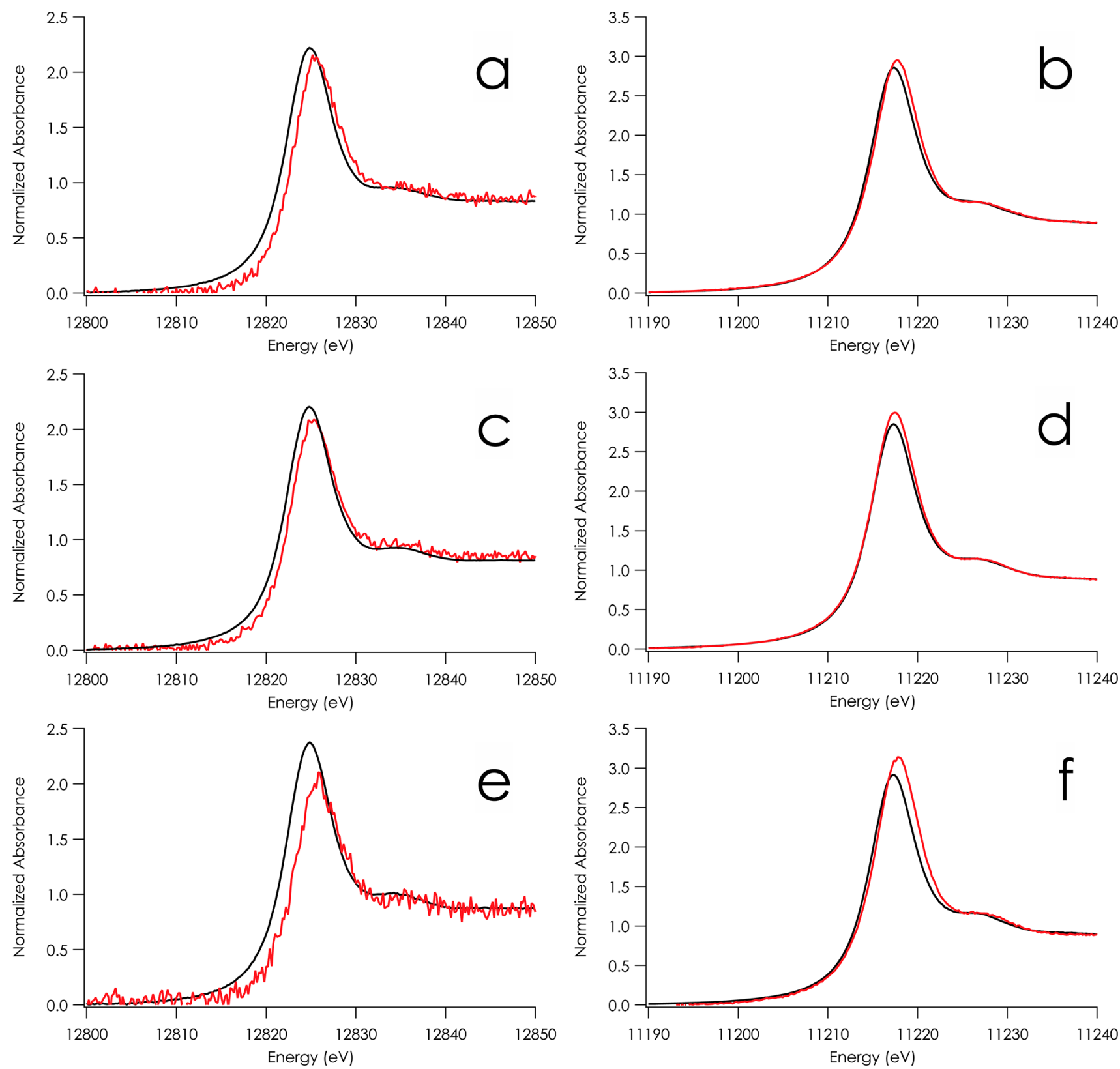

Figure 4. Ir $\mathrm{L}_{3,2}$-edge XAS of neutral (black) and monocationic (red) complexes: 1 (a: $\left.\mathrm{L}_{2}, \mathrm{~b}: \mathrm{L}_{3}\right), 2$ (c: $\left.\mathrm{L}_{2}, \mathrm{~d}: \mathrm{L}_{3}\right), 4\left(\mathrm{e}: \mathrm{L}_{2}, \mathrm{f:} \mathrm{L}_{3}\right)$.

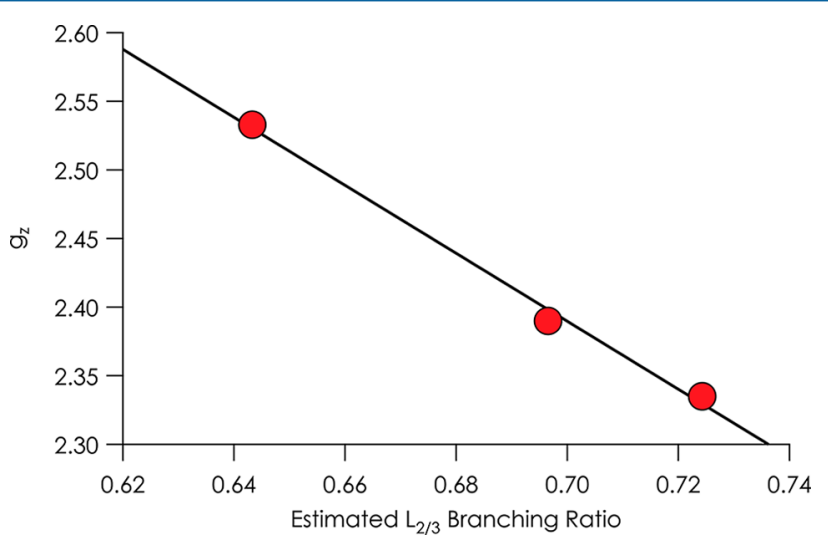

Figure 5. Correlation of experimental $g_{z}$ and EBR for $[1]^{+},[2]^{+}$, and $[4]^{+}\left(R^{2}=0.99\right)$.

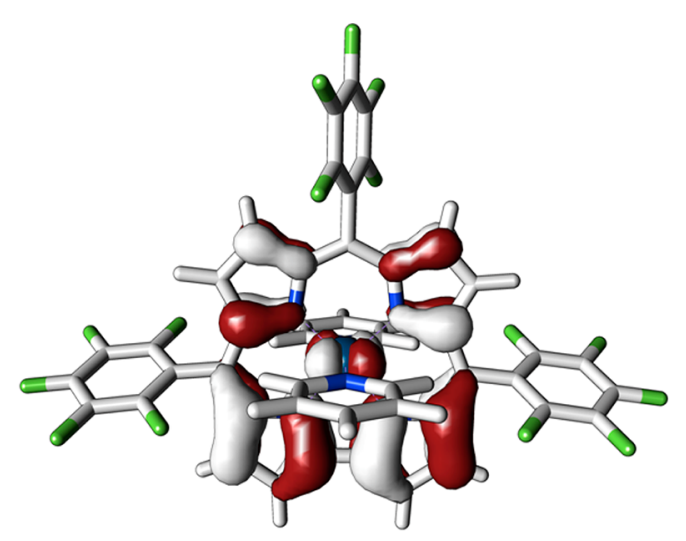

Figure 6. Surface plot of the SOMO of $[2]^{+}$. This orbital is predominantly tpfc $\pi^{*}$ in character with $12.9 \%$ Ir $\mathrm{d}_{x z, y z}$ contribution. The orbital is plotted at an isovalue of 0.03 . 
Table 3. B3LYP/def2-TZVP(-f)+ZORA Calculated Spectroscopic Features and Spin Populations for $\left[\mathbf{M}(\mathrm{tpfc}) \mathbf{L}_{2}\right]^{+}(\mathbf{M}=\mathbf{C o}, \mathbf{R h}, \mathbf{I r})$ Complexes

\begin{tabular}{lcccc}
\multicolumn{1}{c}{ complex } & $g_{z}$ & $\langle g\rangle$ & $\begin{array}{c}\text { SOMO } \rightarrow \\
\text { LUMO }^{a}\end{array}$ & $\begin{array}{c}\text { M spin } \\
\text { population (\%) }\end{array}$ \\
{$[\mathbf{1}]^{+}$} & 2.333 & 2.135 & 16920 & 10.6 \\
{$[2]^{+}$} & 2.409 & 2.167 & 16830 & 12.9 \\
{$[3]^{+}$} & 2.431 & 2.194 & 16790 & 14.1 \\
{$[4]^{+}$} & 2.677 & 2.267 & 16740 & 16.3 \\
& & & & \\
{$\left[\mathrm{Co}(\mathrm{tpfc})(\mathrm{py})_{2}^{+}\right]$} & & 2.008 & & 0.0 \\
{$\left[\mathrm{Rh}(\mathrm{tpfc})\left(\mathrm{py}_{2}{ }^{+}\right]\right.$} & & 2.003 & & 0.0 \\
${ }^{a}$ Energy in $\mathrm{cm}^{-1}$. & & & & \\
\hline
\end{tabular}

electron value. Calculations also reproduce the substantial anisotropy of the monocationic Ir congeners. The calculated values of $g_{z}$ are overestimated relative to experiment, but correlate linearly with experimental values (Figure 7a). Strong correlation is also exhibited between $g_{z}$ and the calculated percentage of metal character in the SOMO (Figure $7 \mathrm{~b}$ ). Likewise, a correlation is found between estimated $\mathrm{L}_{2 / 3}$ branching ratios and calculated spin populations on Ir (Figure 7c).

Single point B3LYP/def2-TZVP(-f)+ZORA solutions were used as starting points for TD-DFT calculations of singlet $\rightarrow$ singlet excitations in neutral and monocationic Ir corrolato complexes (Figure 8). Qualitatively, most of the spectral changes effected by one-electron oxidation are well-reproduced by theory, although features are predicted to arise at $\sim 2,000$ $\mathrm{cm}^{-1}$ higher energy relative to experiment. In accord with experiment, Soret bands are blue-shifted by approximately $4,000 \mathrm{~cm}^{-1}$ upon oxidation. However, the intensity redistribution of the Soret region is poorly modeled. This is likely a fundamental consequence of using the DFT model, which does not account for configuration interaction or SOC effects. This prohibits inclusion of the contributions to the Soret from MLCT bands mixing with intraligand transitions as well as contributions from transitions producing higher multiplicity excited states. However, the loss of Q-band intensity upon oxidation is reproduced qualitatively, as is the growth of a new, lower energy band near $17,000 \mathrm{~cm}^{-1}$ that arises primarily from SOMO to LUMO CT. TD-DFT calculations demonstrate further agreement between calculated electronic structures and spectroscopic observables; calculated SOMO $\rightarrow$ LUMO excitation energies are strongly and linearly correlated with experimental values (Figure $7 \mathrm{~d}$ ).

Returning to eq $2, g_{z}$ depends upon excitations from $\mathrm{d}_{x z}$ and $\mathrm{d}_{y z}$ to the SOMO. Given the consistent agreement displayed between experimental and theoretical trends thus far, the LF excitations among the monocationic Ir corroles should be wellpredicted relative to one another. Ir LF transitions in the monocations are calculated to lie deep in the infrared near $7,000 \mathrm{~cm}^{-1}$, which places them beyond our experimental window (Figure 9, Table 4). However, inputting these excitation energies along with the calculated spin populations and experimental values of $g_{z}$ into eq 3 results in a calculated
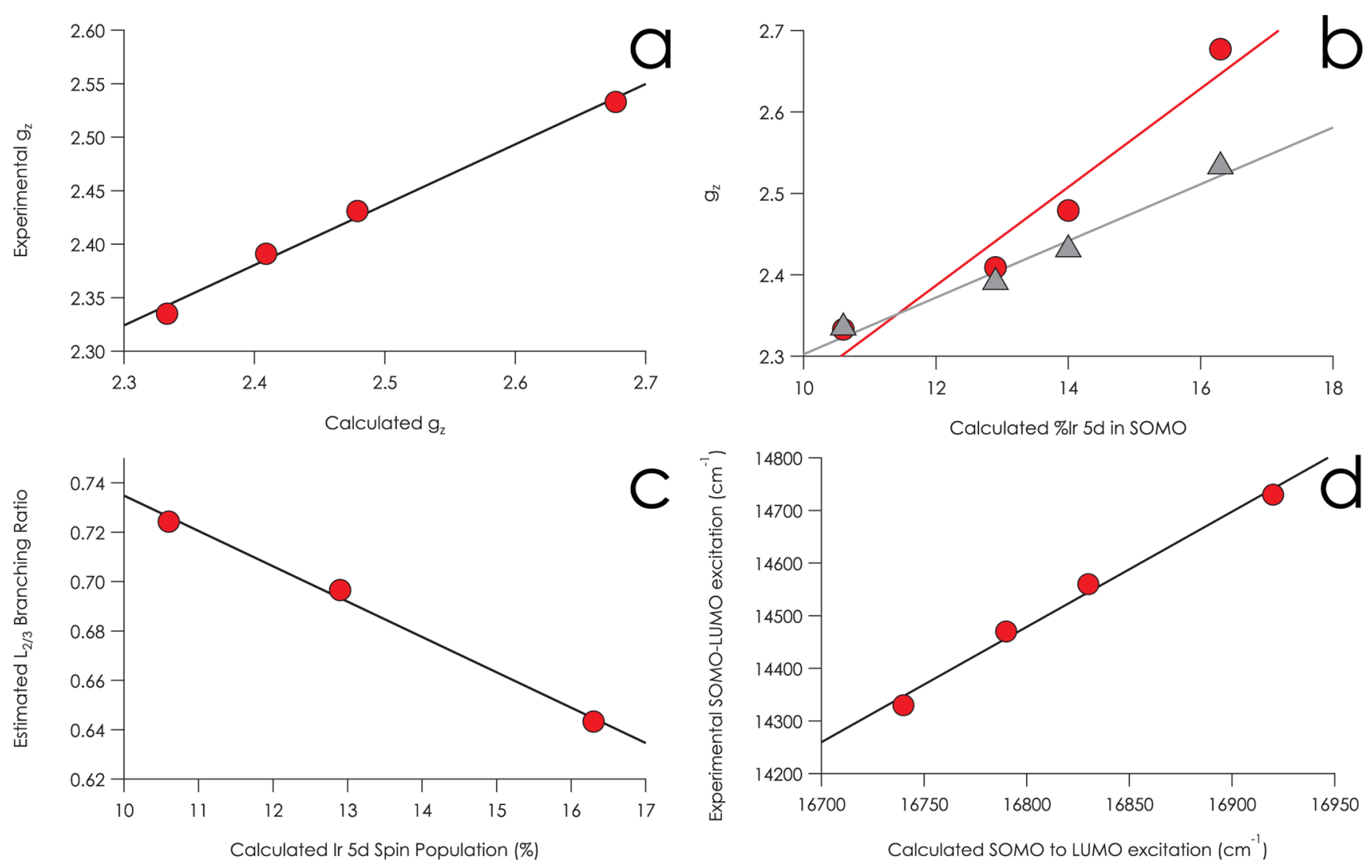

Figure 7. Linear correlations between experimental observables and B3LYP/def2-TZVP(-f)+ZORA calculated values. (a) Experimental vs calculated values of $\left[1-\mathrm{L}_{2}\right]^{+} g_{z}\left(R^{2}=0.99\right)$; (b) calculated SOMO \%Ir spin population vs experimental (gray; $\left.R^{2}=0.97\right)$ and calculated (red; $\left.R^{2}=0.94\right)$ values of $g_{z}$ for $\left[1-L_{2}\right]^{+}$; (c) EBR vs calculated SOMO \%Ir spin population $\left(R^{2}=0.99\right)$; (d) experimental vs calculated SOMO $\rightarrow$ LUMO excitations $\left(R^{2}=\right.$ 0.99 ). 

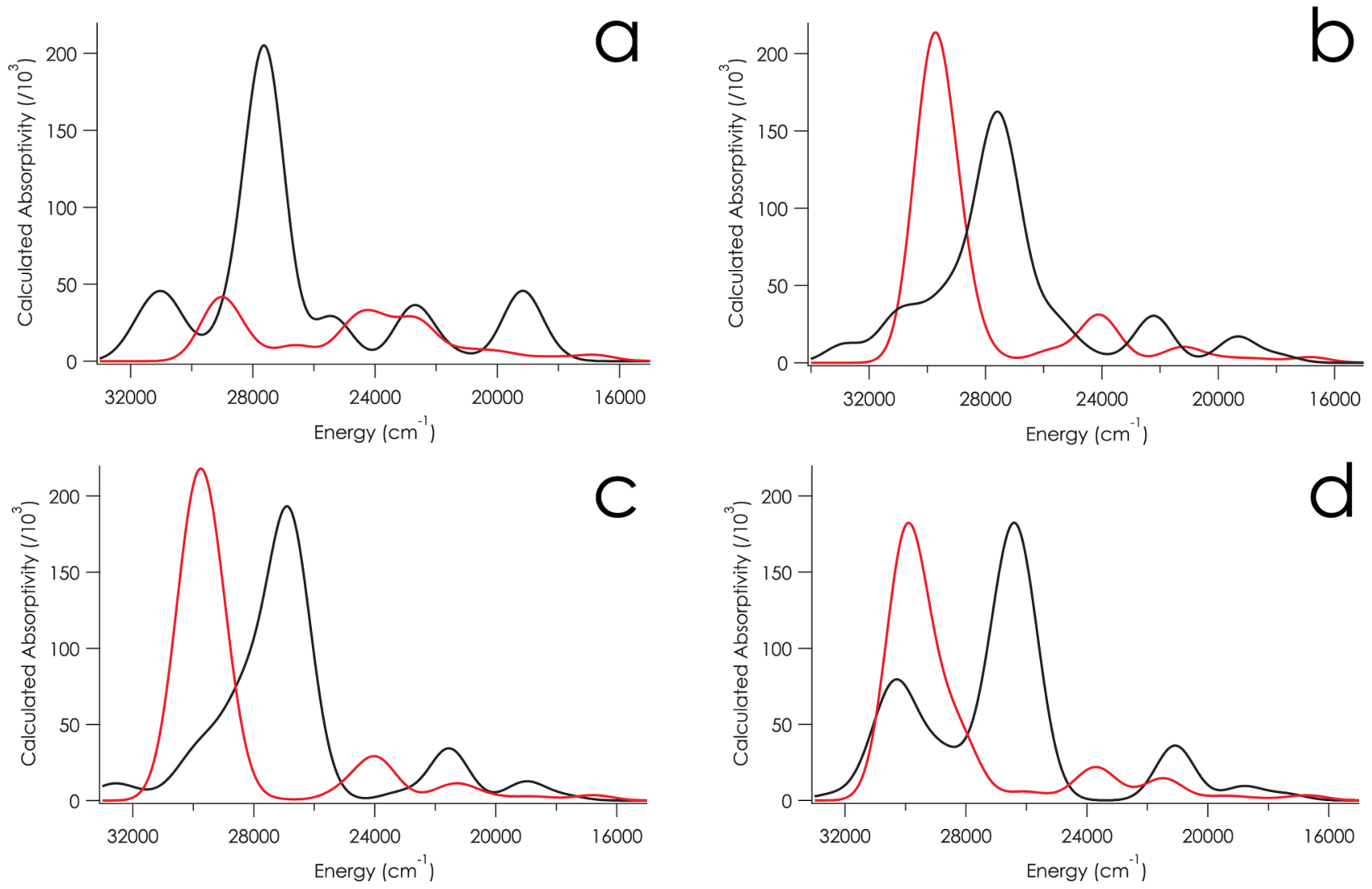

Figure 8. TD-DFT calculations of the electronic absorption spectra of (a) $[1]^{0 /+} ;(b)[2]^{0 /+} ;$ (c) $[3]^{0 /+}$; (d) $[4]^{0 /+}$. Neutral species are in black, monocations are in red.

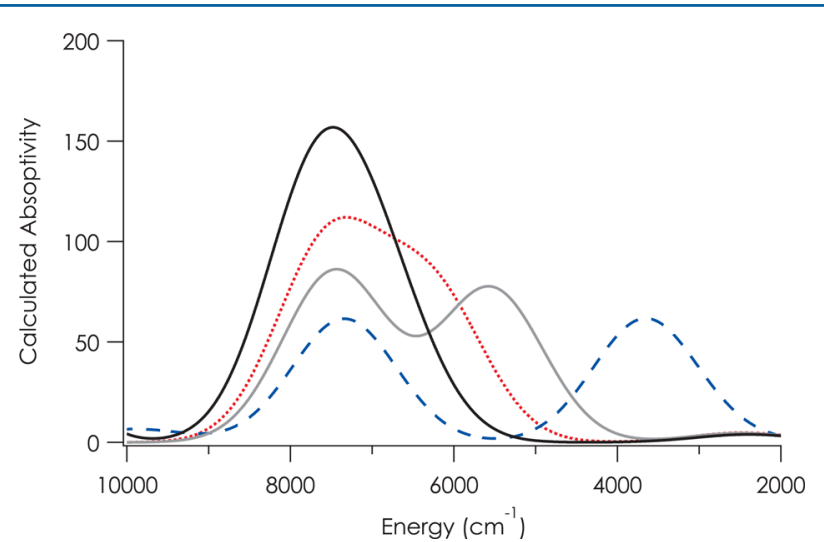

Figure 9. TD-DFT calculated LF bands of $[1]^{+}$(black, solid), $[2]^{+}$ (red, dotted), $[3]^{+}$(gray, solid), $[4]^{+}$(blue, dashed).

Table 4. B3LYP/def2-TZVP(-f)+ZORA Calculated LF Excitations for $\left[\operatorname{Ir}(\operatorname{tpfc}) \mathrm{L}_{2}\right]^{+}$Complexes

$\begin{array}{ccc}\text { complex } & \mathrm{SOMO} \rightarrow \mathrm{d}_{x z}{ }^{a} & \mathrm{SOMO} \rightarrow \mathrm{d}_{y z}{ }^{a} \\ {[1]^{+}} & 7700 & 6880 \\ {[2]^{+}} & 7530 & 6270 \\ {[3]^{+}} & 7450 & 5550 \\ {[4]^{+}} & 8250 & 7340\end{array}$

${ }^{a}$ Energy in $\mathrm{cm}^{-1}$.

SOC constant $\lambda$ of $5500 \pm 600 \mathrm{~cm}^{-1}$ for the series. The selfconsistency of $\lambda$ lends further credence to our hypothesis that Ir admixture governs the observed values of $g_{z}$. However, the absolute values of $\lambda$ are likely overestimated. The free-ion $\lambda$ for
$\mathrm{Ir}^{\mathrm{IV}}$ has been estimated ${ }^{45}$ near $5000 \mathrm{~cm}^{-1}$, while magnetic susceptibility data and magnetic circular dichroism experiments give respective values of $2100^{46}$ and $2800^{47} \mathrm{~cm}^{-1}$ for $\lambda$ in $\left[\mathrm{Ir}^{\mathrm{IV}} \mathrm{Cl}_{6}\right]^{2-}$.

Relativistic Effects in M-Corrole Bonding. Our data indicate that the anisotropy of the EPR spectra exhibited by monocationic Ir corroles is primarily attributable to mixing between $\mathrm{Ir} 5 \mathrm{~d}$ and corrolato $\pi$ orbitals, with the variations among $g$-values reflective of the magnitude of this mixing. The consensus electronic structural formulation that emerges for these species is of a highly covalent system wherein unpaired density is spread across the metal and the ligand. This description distinguishes the Ir complexes from their lighter Group 9 congeners, whose monocations completely lack $\mathrm{M}^{\mathrm{IV}}$ character; the redox-active MOs of these latter molecules are entirely localized on the ligand. Notably, this distinction does not arise because of differences in the relative magnitudes of SOC alone. Rather, the high energy and diffuse nature of Ir 5d orbitals affords the impetus for the observed iridium $5 \mathrm{~d}$ orbital character in monocationic Ir corroles. ${ }^{48}$ Relativistic contraction of Ir core $\mathrm{s}$ and $\mathrm{p}$ orbitals results in shielding of the $5 \mathrm{~d}$ orbitals, permitting greater radial diffusion and affording a mechanism for greater overlap with the corrole $\pi$ system. Case in point, repeating our calculation of $2^{+}$without explicit relativistic correction (B3LYP/def2-TZVP(-f) without ZORA) results in a decrease in Ir spin population from 12.9 to $4.7 \%$. Similar findings about bonding in Group 9 bis(borylene) complexes have been attributed to relativistic effects as well. ${ }^{49}$ 


\section{CONCLUSIONS}

The cationic iridium corrole complexes discussed here have been described in the literature using two different limiting formalisms, $\left\{\left[\operatorname{Ir}^{\mathrm{III}}\left(\mathrm{tpfc}^{\bullet}\right) \mathrm{L}_{2}\right]^{+} \leftrightarrow\left[\mathrm{Ir}^{\mathrm{IV}}(\mathrm{tpfc}) \mathrm{L}_{2}\right]^{+}\right\}$. Our new data suggest these limiting situations, which explicitly refer to a "corrole-based" or a "metal-based" SOMO, respectively, cannot accurately describe the frontier electronic structure of [Ir$\left.(\mathrm{tpfc}) \mathrm{L}_{2}\right]^{+}$complexes. It is tempting to make the claim that these complexes are yet another example of metallocorroles with ligand-based redox-active orbitals. However, we have shown that the percentage of Ir character in the SOMO has important, observable physical ramifications even with only small amounts of $5 \mathrm{~d}$ admixture into a largely ligand-centered SOMO. The reduction potentials and electronic spectra of the complexes are profoundly affected by changes to the Ir character in the SOMO on the order of a few percent, so clearly an $\left[\operatorname{Ir}^{\mathrm{III}}\left(\operatorname{tpfc}^{\bullet}\right) \mathrm{L}_{2}\right]^{+}$description is inadequate to describe the electronic structures of these complexes in spite of the apparently minor contribution of metal $\mathrm{d}$ orbitals to the SOMO. Therefore, we posit that systems such as those discussed here must be described in terms of fully molecular redox activity, but we note that such a description neither precludes nor invalidates detailed discussion of metal-ligand admixture in redox-active orbitals. Our results also suggest that isolated examination of individual parameters such as $\mathrm{g}$ anisotropy, reduction potential, or changes in covalency (via XAS spectra), is insufficient to determine the d electron counts of metals ligated by redox non-innocent scaffolds. A cogent, self-consistent chemical story must be presented by a concerted analysis using multiple methods. Additionally, our data highlight the importance of relativistic effects in encouraging overlap between metal and ligand orbitals, suggesting that many late third-row congeners of known metal complexes will display similar behavior.

\section{ASSOCIATED CONTENT}

\section{S Supporting Information}

$\mathrm{CV}$ of 1-4, Ir L-edge XAS of oxidation state standards, $\mathrm{Ir} \mathrm{L}_{3^{-}}$ edge EXAFS functional dependence of DFT calculations, coordinates of geometry-optimized molecules, low-spin $\mathrm{d}^{5} \mathrm{~g}$ matrix for mixed SOMO. This material is available free of charge via the Internet at http://pubs.acs.org.

\section{AUTHOR INFORMATION}

\section{Corresponding Author}

*E-mail: jp3204@columbia.edu (J.H.P.), kml236@cornell.edu (K.M.L.).

\section{Present Address}

${ }^{\dagger}$ Department of Chemistry, Columbia University, New York, New York 10027, United States.

\section{Notes}

The authors declare no competing financial interest.

\section{ACKNOWLEDGMENTS}

J.H.P. and K.M.L. are grateful to their friend and mentor Prof. Harry B. Gray for his enthusiastic support over the years. J.H.P. and K.M.L. thank Prof. Dr. Serena DeBeer for technical assistance, Dr. Stephen Sproules for helpful discussion, and Prof. Chad A. Lewis for use of his LC-MS. This work was supported by the Arnold and Mabel Beckman Foundation as well as a startup grant to K.M.L. from Cornell University. Portions of this research were carried out at the Stanford
Synchrotron Radiation Lightsource, a Directorate of SLAC National Accelerator Laboratory and an Office of Science User Facility operated for the U.S. Department of Energy Office of Science by Stanford University.

\section{LIST OF ABBREVIATIONS USED}

$\begin{array}{ll}\text { COD } & \text { 1,5-cyclooctadiene } \\ \text { CV } & \text { cyclic voltammetry } \\ \text { COSMO } & \text { conductor-like screening model } \\ \text { CT } & \text { charge transfer } \\ \text { DFT } & \text { density functional theory } \\ \text { EBR } & \text { estimated branching ratio } \\ \text { EPR } & \text { electron paramagnetic resonance } \\ \text { EXAFS } & \text { extended X-ray absorption fine structure } \\ \text { HFC } & \text { hyperfine coupling } \\ \text { LC-MS } & \text { liquid chromatography mass spectrometry } \\ \text { LF } & \text { ligand field } \\ \text { LUMO } & \text { lowest unoccupied molecular orbital } \\ \text { MLCT } & \text { metal-to-ligand charge transfer } \\ \text { MO } & \text { molecular orbital } \\ \text { NMR } & \text { nuclear magnetic resonance } \\ \text { QRO } & \text { quasi-restricted orbital } \\ \text { SARC } & \text { segmented all-electron relativistically contracted } \\ \text { SHFC } & \text { superhyperfine coupling } \\ \text { SOC } & \text { spin-orbit coupling } \\ \text { SOMO } & \text { singly occupied molecular orbital } \\ \text { THF } & \text { tetrahydrofuran } \\ \text { TD-DFT } & \text { time-dependent density functional theory } \\ \text { UKS } & \text { unrestricted Kohn-Sham } \\ \text { USB } & \text { universal service bus } \\ \text { UV-vis } & \text { ultraviolet-visible } \\ \text { XAS } & \text { X-ray absorption spectroscopy } \\ \text { ZORA } & \text { zeroth-order relativistic approximation } \\ & \end{array}$

\section{REFERENCES}

(1) (a) Chirik, P. J. Inorg. Chem. 2011, 50, 9737-9740. (b) Lyaskovskyy, V.; de Bruin, B. ACS Catal. 2012, 2, 270-279.

(2) Jørgensen, C. K. Coord. Chem. Rev. 1966, 1, 164-178.

(3) (a) Banerjee, P.; Sproules, S.; Weyhermüller, T.; DeBeer George, S.; Wieghardt, K. Inorg. Chem. 2009, 48, 5829-5847. (b) Eisenberg, R.; Gray, H. B. Inorg. Chem. 2011, 50, 9741-9751. (c) Sproules, S.; Banerjee, P.; Weyhermüller, T.; Yan, Y.; Donahue, J. P.; Wieghardt, K. Inorg. Chem. 2011, 50, 7106-7122. (d) Sproules, S.; Benedito, F. L.; Bill, E.; Weyhermüller, T.; DeBeer George, S.; Wieghardt, K. Inorg. Chem. 2009, 48, 10926-10941. (e) Sproules, S.; Weyhermüller, T.; DeBeer, S.; Wieghardt, K. Inorg. Chem. 2010, 49, 5241-5261.

(4) (a) Bowman, A. C.; Sproules, S.; Wieghardt, K. Inorg. Chem. 2012, 51, 3707-3717. (b) Scarborough, C. C.; Lancaster, K. M.; DeBeer, S.; Weyhermüller, T.; Sproules, S.; Wieghardt, K. Inorg. Chem. 2012, 51, 3718-3732. (c) Scarborough, C. C.; Sproules, S.; Weyhermüller, T.; DeBeer, S.; Wieghardt, K. Inorg. Chem. 2011, 50, 12446-12462.

(5) (a) Trovitch, R. J.; Lobkovsky, E.; Chirik, P. J. Inorg. Chem. 2006, 45, 7252-7260. (b) Bart, S. C.; Chłopek, K.; Bill, E.; Bouwkamp, M. W.; Lobkovsky, E.; Neese, F.; Wieghardt, K.; Chirik, P. J. J. Am. Chem. Soc. 2006, 128, 13901-13912. (c) Bowman, A. C.; Milsmann, C.; Atienza, C. C. H.; Lobkovsky, E.; Wieghardt, K.; Chirik, P. J. J. Am. Chem. Soc. 2010, 132, 1676-1684. (d) Bowman, A. C.; Milsmann, C.; Bill, E.; Lobkovsky, E.; Weyhermüller, T.; Wieghardt, K.; Chirik, P. J. Inorg. Chem. 2010, 49, 6110-6123.

(6) Frazier, B. A.; Bartholomew, E. R.; Wolczanski, P. T.; DeBeer, S.; Santiago-Berrios, M. Ä.; Abruña, H. D.; Lobkovsky, E. B.; Bart, S. C.; Mossin, S.; Meyer, K.; Cundari, T. R. Inorg. Chem. 2011, 50, 1241412436. 
(7) (a) Griffiths, J. H. E.; Owen, J. Proc. R. Soc. London, Ser. A 1954, 226, 96-111. (b) Stevens, K. W. H. Proc. R. Soc. London, Ser. A 1953, $219,542-555$.

(8) (a) Solomon, E. I.; Szilagyi, R. K.; George, S. D.; Basumallick, L. Chem. Rev. 2004, 104, 419-458. (b) Warren, J. J.; Lancaster, K.M.; Richards, J. H.; Gray, H. B. J. Inorg. Biochem. 2012, 115, 119-126.

(9) (a) Palmer, J. H. Struct. Bonding (Berlin) 2012, 142, 49-89. (b) Ghosh, A.; Steene, E. J. Inorg. Biochem. 2002, 91, 423-436.

(10) (a) Roos, B. O.; Veryazov, V.; Conradie, J.; Taylor, P. R.; Ghosh, A. J. Phys. Chem. B 2008, 112, 14099-14102. (b) Ghosh, A.; Wondimagegn, T.; Parusel, A. B. J. J. Am. Chem. Soc. 2000, 122, 51005104. (c) Hocking, R. K.; George, S. D.; Gross, Z.; Walker, F. A.; Hodgson, K. O.; Hedman, B.; Solomon, E. I. Inorg. Chem. 2009, 48, $1678-1688$

(11) (a) Murakami, Y.; Matsuda, Y.; Sakata, K.; Sunao, Y.; Tanaka, Y., Aoyama Y. (1981) Bull. Chem. Soc. Jpn. 1981, 54, 163-169; (b) Bröring, M.; Brégier, F.; Tejero, E. C.; Hell, C.; Holthausen, M. C. Angew. Chem., Int. Ed. 2007, 46, 445-448.

(12) (a) Will, S.; Lex, J.; Vogel, E.; Schmickler, H.; Gisselbrecht, J.-P.; Haubtmann, C.; Bernard, M.; Gross, M. Angew. Chem., Int. Ed. Engl. 1997, 36, 357-361. (b) Brückner, C.; Briñas, R. P.; Krause-Bauer, J. A. Inorg. Chem. 2003, 42, 4495-4497. (c) Wasbotten, I. H.; Wondimagegn, T.; Ghosh, A. J. Am. Chem. Soc. 2003, 124, 81048116.

(13) (a) Simkhovich, L.; Goldberg, I.; Gross, Z. Inorg. Chem. 2002, 41, 5433-5439. (b) Simkhovich, L.; Gross, Z. Inorg. Chem. 2004, 43, $6136-6138$.

(14) (a) Cai, S.; Walker, F. A.; Licoccia, S. Inorg. Chem. 2000, 39, 3466-3478. (b) Zakharieva, O.; Schünemann, V.; Gerdan, M.; Licoccia, S.; Cai, S.; Walker, F. A.; Trautwein, A. X. J. Am. Chem. Soc. 2002, 124, 6636-6648. (c) Yatsunyk, L.; Walker, F. A. Inorg. Chim. Acta 2002, 337, 266-274. (d) Cai, S.; Licoccia, S.; D’Ottavi, C.; Paolesse, R.; Nardis, S.; Bulach, V.; Bertrand, Z.; Shokhivera, T. K.; Walker, F. A. Inorg. Chim. Acta 2002, 339, 171-178.

(15) (a) Walker, F. A.; Licoccia, S.; Paolesse, R. J. Inorg. Biochem. 2006, 100, 810-837. (b) Ye, S.; Tuttle, T.; Bill, E.; Simkhovich, L.; Gross, Z.; Thiel, W.; Neese, F. Chem.-Eur. J. 2008, 14, 1083910851.

(16) (a) Aviv-Harel, I.; Gross, Z. Chem.-Eur. J. 2009, 15, 83828394. (b) Aviv, I.; Gross, Z. Chem. Commun. 2007, 1987-1999.

(17) (a) Gross, Z.; Golubkov, G.; Simkhovich, L. Angew. Chem., Int. Ed. 2000, 39, 4045-4047. (b) Simkhovich, L.; Mahammed, A.; Goldberg, I.; Gross, Z. Chem.-Eur. J. 2001, 7, 1041-1055. (c) Mahammed, A.; Gray, H. B.; Meier-Callahan, A. E.; Gross, Z. J. Am. Chem. Soc. 2003, 125, 1162-1163. (d) Gross, Z.; Gray, H. B. Adv. Synth. Catal. 2004, 346, 165-170. (e) Mahammed, A.; Gross, Z. Chem. Commun. 2010, 46, 7040-7042.

(18) (a) Agadjanian, H.; Ma, J.; Rentsendorj, A.; Valluripalli, V.; Hwang, J. Y.; Mahammed, A.; Farkas, D. L.; Gray, H. B.; Gross, Z.; Medina-Kauwe, L. K. Proc. Natl. Acad. Sci. U.S.A. 2009, 106 (15), 6105-6110. (b) Haber, A.; Mahammed, A.; Fuhrman, B.; Volkova, N.; Coleman, R.; Hayek, T.; Aviram, M.; Gross, Z. Angew. Chem., Int. Ed. 2008, 47, 7896-7900.

(19) Flamigni, L.; Gryko, D. T. Chem. Soc. Rev. 2009, 38, 1635-1646. (20) Palmer, J. H.; Day, M. W.; Wilson, A. D.; Henling, L. M.; Gross, Z.; Gray, H. B. J. Am. Chem. Soc. 2008, 130, 7786-7787.

(21) Palmer, J. H.; Brock-Nannestad, T.; Mahammed, A.; Durrell, A. C.; VanderVelde, D.; Virgil, S.; Gross, Z.; Gray, H. B. Angew. Chem., Int. Ed. 2011, 50, 9433-9436.

(22) Palmer, J. H.; Durrell, A. C.; Gross, Z.; Winkler, J. R.; Gray, H. B. J. Am. Chem. Soc. 2010, 132, 9230-9231.

(23) Palmer, J. H.; Mahammed, A.; Lancaster, K. M.; Gross, Z.; Gray, H. B. Inorg. Chem. 2009, 48, 9308-9315.

(24) Dong, S. S.; Nielsen, R. J.; Palmer, J. H.; Gray, H. B.; Gross, Z.; Dasgupta, S.; Goddard, W. A. Inorg. Chem. 2011, 50, 764-770.

(25) Gross, Z.; Galili, N.; Simkhovich, L.; Saltsman, I.; Botoshansky, M.; Bläser, D.; Boese, R.; Goldberg, I. Org. Lett. 1999, 1, 599-602.

(26) Golombek, A. P.; Hendrich, M. P. J. Magn. Reson. 2003, 165, $33-48$.
(27) George, G. N. EXAFSPAK; Stanford Synchrotron Radiation Lightsource, Stanford Linear Accelerator Center, Stanford University: Stanford, CA, 2001.

(28) (a) DeLeon, J. M.; Rehr, J. J.; Zabinsky, S. I.; Albers, R. C. Phys. Rev. B. 1991, 44, 4146-4156. (b) Rehr, J. J.; DeLeon, J. M.; Zabinsky, S. I.; Albers, R. C. J. Am. Chem. Soc. 1991, 113, 5135-5140.

(29) Neese, F.; Wennmohs, F.; Becker, U.; Ganyushin, D.; Hansen, A.; Liakos, D. G.; Kollmar, C.; Kossmann, S.; Petrenko, T.; Reimann, C.; Riplinger, C.; Sivalingam, K.; Valeev, E.; Wezisla, B. ORCA, 2.8.0; University of Bonn: Bonn, Germany, 2010.

(30) Perdew, J. P.; Wang, Y. Phys. Rev. B 1992, 45, 13244-13249.

(31) Pantazis, D. A.; Chen, X.-Y.; Landis, C. R.; Neese, F. J. Chem. Theor. Comput. 2008, 4, 908-919.

(32) (a) van Lenthe, E.; van der Avoird, A.; Wormer, P. E. S. J. Chem. Phys. 1998, 108, 4783-4796. (b) van Wüllen, C. J. Chem. Phys. 1998, 109, 392-399.

(33) Grimme, S.; Antony, J.; Ehrlich, S.; Krieg, H. J. Chem. Phys. 2010, 132, 154104.

(34) Klamt, A.; Schüurmann, G. J. Chem. Soc., Perkin Trans. 21993 799-805.

(35) (a) Becke, A. D. J. Chem. Phys. 1993, 98, 1372-1377. (b) Lee, C. T.; Yang, W. T.; Parr, R. G. Phys. Rev. B 1988, 37, 785-789. (c) Stephens, P. J.; Devlin, F. J.; Chabalowski, C. F.; Frisch, M. J. J. Phys. Chem. 1994, 98, 11623-11627.

(36) Neese, F. J. Chem. Phys. 2001, 115, 034107.

(37) Neese, F. J. Chem. Phys. 2005, 122, 1-13.

(38) Neese, F. J. Am. Chem. Soc. 2006, 128, 10213-10222.

(39) Weigend, F.; Ahlrichs, R. Phys. Chem. Chem. Phys. 2005, 7, 3297-3305.

(40) Scheibel, M. G.; Askevold, B.; Heinemann, F. W.; Reijerse, E. J.; de Bruin, B.; Schneider, S. Nat. Chem. 2012, 4, 552-558.

(41) (a) Rieger, P. H. Coord. Chem. Rev. 1994, 135 (Äì136), 203286. (b) Mabbs, F. E.; Machin, D. J. Magnetism and Transition Metal Complexes; Dover Publications, Inc.: Mineola, NY, 2008.

(42) (a) Koshino, M.; Kurata, H.; Isoda, S.; Kobayashi, T. Micron 2000, 31, 373-380. (b) Wang, H.; Ge, P.; Riordan, C. G.; Brooker, S.; Woomer, C. G.; Collins, T.; Melendres, C. A.; Graudejus, O.; Bartlett, N.; Cramer, S. P. J. Phys. Chem. B 1998, 102, 8343-8346. (c) Thole, B. T.; van der Laan, G. Phys. Rev. B 1988, 38, 3158-3171.

(43) Kosog, B.; La Pierre, H. S.; Denecke, M. A.; Heinemann, F. W.; Meyer, K. Inorg. Chem. 2012, 51, 7940-7944.

(44) Beamtime constraints prevented collection of XAS data for 3 and $[3]^{+}$.

(45) Figgis, B. N. Introduction to Ligand Fields; Interscience Publishers: New York, 1966.

(46) Cooke, A. H.; Lazenby, R.; McKim, F. R.; Owen, J.; Wolf, W. P. Proc. R. Soc. London Ser. A 1959, 250, 97-109.

(47) Keiderling, T. A.; Stephens, P. J.; Piepho, S. B.; Slater, J. L.; Schatz, P. N. Chem. Phys. 1975, 11, 343-348.

(48) (a) Miao, M.-S.; Seshadri, R. J. Phys. Condens. Matter 2012, 24, 215503. (b) Pyykkö, P. Annu. Rev. Phys. Chem. 2012, 63, 45-64.

(49) Pandey, K. K. Organometallics 2011, 30, 5851-5858. 